\title{
Effect of Acute Hyperglycaemia on Plasma Potassium and Aldosterone Levels in Type 2 (Non-Insulin-Dependent) Diabetes
}

\author{
J. Rosenstock, S. A. Loizou, I. E. Brajkovich, K. Mashiter and G. F.Joplin \\ Endocrine Unit, Department of Medicine, Royal Postgraduate Medical School, Hammersmith Hospital, London, UK
}

\begin{abstract}
Summary. Potassium homeostasis during a 50-g oral glucose tolerance test was studied in 14 newly diagnosed, untreated Type 2 (non-insulin-dependent) diabetics. They showed a rise in plasma potassium from a mean \pm SEM basal of $3.9 \pm 0.1$ to $4.4 \pm 0.1 \mathrm{mmol} / 1$ at $60 \mathrm{~min}$ and to $4.6 \pm 0.1 \mathrm{mmol} / 1$ at $90 \mathrm{~min}(p<0.01)$, whereas no change was seen in a group of 14 normal subjects. A possible role of mineralocorticoids was sought by measuring simultaneous serum aldosterone and deoxycorticosterone levels. Aldosterone was reduced after the glucose load in all subjects studied, falling to $73 \%$ of basal at $60 \mathrm{~min}$ in diabetics $(p<0.01)$, and to $61 \%$ of basal at $90 \mathrm{~min}$ in normal subjects $(p<0.001)$. Serum deoxycorticosterone showed a similar pattern. Thus it is unlikely that the rise in plasma potassium seen in the diabetic patients was due to abnormal levels of mineralocorticoids. Since the diabetic subjects were found to have an intact insulin response to the glucose load, it is suggested that resistance to insulin-stimulated potassium uptake into cells might be involved in the pathogenesis of the paradoxical hyperkalaemia induced by acute hyperglycaemia.
\end{abstract}

Key words: Type 2 diabetes, plasma potassium, insulin resistance, aldosterone, deoxycorticosterone, plasma renin activity.

Previous reports have shown that potentially dangerous glucose-induced hyperkalaemia can occur in diabetes [1, 2]. However, most studies [3, 4] were based on insulin-dependent diabetics, and the majority had coexistent selective hyporeninaemic hypoaldosteronism [1,3-5] with some degree of renal impairment as well.
As insulin and aldosterone both have crucial roles in potassium homeostasis [6-8], a combined deficiency of these hormones would predispose to hyperkalaemia when hyperglycaemia induces an osmotically determined redistribution of potassium from the intracellular to the extracellular fluid compartment [1, 9]. Rises in plasma osmolality and potassium have indeed been shown to occur during an oral glucose tolerance test in insulin-dependent diabetics, but the effect of the residual endogenous insulin on net cellular potassium transfer could not be assessed [2]. We therefore selected a group of untreated newly diagnosed non-insulin-dependent diabetic patients in whom to study the effect of an oral glucose load on plasma potassium, in relation to serum insulin and mineralocorticoid responses. These parameters have not hitherto been measured simultaneously in such patients.

\section{Subjects and Methods}

Fourteen unselected and newly discovered diabetic patients and 14 normal volunteers underwent a glucose tolerance test. Informed consent was obtained from the subjects and approval from the Hospital Ethical Committee. In all the patients the diagnosis of diabetes mellitus was made on the basis of symptoms of polyuria and polydipsia, with a fasting plasma glucose level $>6 \mathrm{mmol} / 1$ and at least two values $>11 \mathrm{mmol} / 1$ during the glucose tolerance test. Subsequently, most of the diabetic patients were satisfactorily controlled with a hypocaloric diet alone or with the addition of oral hypoglycaemic agents; none required insulin treatment. All were normotensive, none were on salt-restricted diets or any drugs, and none had diabetic retinopathy or nephropathy. 

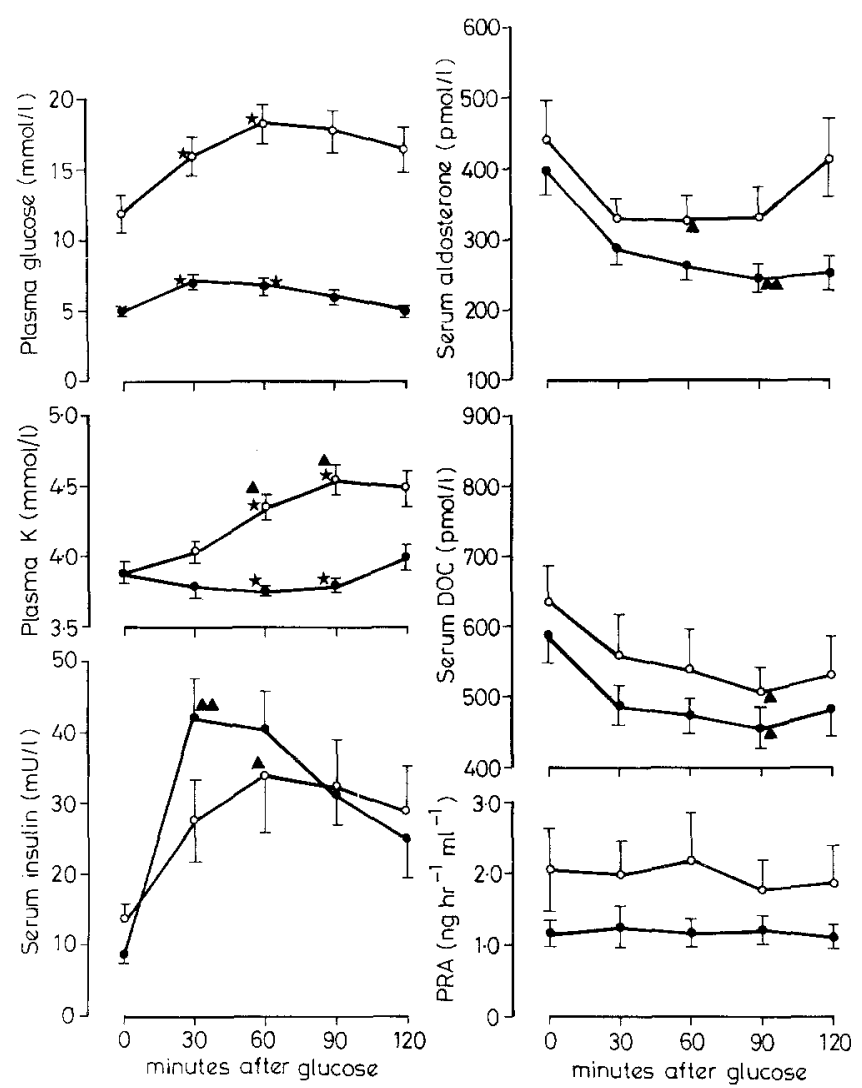

Fig. 1. Plasma potassium changes during oral glucose tolerance tests in relation to serum insulin and mineralocorticoid responses. All values plotted are group means \pm SEM. jects; $\bigcirc-O$ diabetic subjects. ${ }^{*} p<0.001$ : significance of difference between values for both groups. $\boldsymbol{\Delta} p<0.01 ; \boldsymbol{\Lambda} \Delta p<0.001$ : changes from basal within each group. Serum $D O C=$ deoxycorticosterone; $P R A=$ plasma renin activity

The diabetic group consisted of 12 men, aged 28-78 years (mean 52 years) and two women, aged 41 and 49 years. Eleven were Caucasoid, two were Asian and one was African. Five patients were within $20 \%$ of ideal body weight [10] and nine were obese (mean $138 \%$ of ideal body weight, range: $126 \%-153 \%$ ).

Fourteen normal Caucasoid subjects on no medication and having no known endocrine or renal disease served as a control group. This group consisted of seven men, aged $25-53$ years (mean 37 years) and seven women, aged $25-72$ years (mean 35 years). Nine control subjects were within $20 \%$ of ideal body weight and five were obese (mean 145\% of ideal body weight, range: $130 \%-177 \%)$.

A conventional glucose tolerance test with $50 \mathrm{~g}$ glucose in $200 \mathrm{ml}$ of water was given to each subject after a 12-h overnight fast and $30 \mathrm{~min}$ of rest in a sitting position. Patients and control subjects were on 'ad libitum' sodium intakes. Subjects sat upright throughout the test which began between 09.00 and
$10.00 \mathrm{~h}$. Blood samples were taken basally and then every $30 \mathrm{~min}$ for $2 \mathrm{~h}$, through an indwelling needle. Serum insulin, aldosterone, deoxycorticosterone, cortisol and plasma potassium, glucose and plasma renin activity were measured. Blood for plasma potassium was immediately centrifuged and special care was taken to avoid any artefactual rise in plasma potassium levels resulting from haemolysis, venous stasis or muscular contraction. Plasma potassium was measured by flame photometry, glucose by a glucose oxidase method using a Technicon autoanalyser, serum aldosterone and deoxycorticosterone by radioimmunoassay without chromatographic purification [11], using highly specific antisera $[12,13]$. Cortisol was measured by competitive protein binding [14], insulin by radioimmunoassay [15] and plasma renin activity using a CIS (Sorin) angiotensin I radioimmunoassay kit. The mean intra- and inter-assay coefficients of variation were $7.3 \%$ and $15.1 \%$ for aldosterone, $8.3 \%$ and $14.2 \%$ for deoxycorticosterone, $7.5 \%$ and $11.8 \%$ for insulin, and $8.1 \%$ and $12.5 \%$ for plasma renin activity. Statistical evaluation was performed using Student's 't-test for paired (within each group) and unpaired (between the two groups) data.

\section{Results}

There were marked differences in mean fasting plasma glucose levels between the groups (Fig. 1): diabetic patients $11.8 \pm 1.3 \mathrm{mmol} / \mathrm{l}$ and normal subjects 4.9 $\pm 0.1 \mathrm{mmol} / 1$ (mean $\pm \mathrm{SEM})$. In the diabetics, the mean plasma glucose showed a rise from the fasting level to a peak of $18.2 \pm 1.4 \mathrm{mmol} / 1(p<0.001)$, whereas the normal subjects, as expected, had no impairment in glucose tolerance, the mean value rising to a peak of $7.1 \pm 0.5 \mathrm{mmol} / \mathrm{l}$ at $30 \mathrm{~min}(p<0.01)$ and falling to $4.9 \pm 0.4 \mathrm{mmol} / 1$ at $120 \mathrm{~min}$.

The normal subjects and diabetic patients had similar basal plasma potassium values (3.9 \pm $0.1 \mathrm{mmol} / 1)$. The diabetic group had a rise at $60 \mathrm{~min}$ to $4.4 \pm 0.1 \mathrm{mmol} / 1$ and at $90 \mathrm{~min}$ to $4.6 \pm 0.1 \mathrm{mmol} / 1$ ( $p<0.01$ when compared with basal levels). All diabetics but one had a plasma potassium rise after the glucose load. No significant changes were noted in the mean potassium values in the normal group. Significant differences were found in potassium levels at 60 and $90 \mathrm{~min}$ when the normal group was compared with the diabetic patients $(p<0.001$ for each).

The diabetic group showed a peak insulin value at $60 \mathrm{~min}$ of $34 \pm 8$ versus $13 \pm 2 \mathrm{mU} / 1$ basally $(p<0.01)$, whereas in normal subjects the peak at $30 \mathrm{~min}$ was $43 \pm 6$ versus $8 \pm 1 \mathrm{mU} / 1$ basally $(p<0.001)$. When the subgroup of obese normal sub- 
jects was analysed separately, results for all their parameters studied appeared no different from the rest of the normal group, except for the insulin response at $30 \mathrm{~min}$, when obese subjects had a peak insulin of 57 $\pm 8 \mathrm{mU} / 1$ and lean subjects $34 \pm 5 \mathrm{mU} / 1(p<0.05)$.

Mean serum aldosterone levels showed a fall in both groups. In normal subjects it fell from a basal of $398 \pm 35$ to $244 \pm 19 \mathrm{pmol} / 1$ at $90 \mathrm{~min}(61 \%$ of basal, $p<0.001)$ and in diabetics at $60 \mathrm{~min}$ from $444 \pm 53$ to $327 \pm 34 \mathrm{pmol} / 1$ ( $73 \%$ of basal, $p<0.01$ ).

Serum deoxycorticosterone behaved in parallel to aldosterone with falls at $90 \mathrm{~min}$ in normal subjects from $588 \pm 40$ to $454 \pm 29 \mathrm{pmol} / 1$ ( $77 \%$ of basal, $p<0.01)$ and in diabetics from $635 \pm 50$ to $504 \pm$ $36 \mathrm{pmol} / 1$ ( $79 \%$ of basal, $p<0.01)$.

Plasma renin activity showed no significant change in any of the groups studied, and serum cortisol simply showed the normal diurnal rhythm.

When all the points from the glucose tolerance test were used, weak positive correlations were found between plasma potassium levels and plasma glucose concentrations in diabetics $(n=70, r=0.35$, $p<0.01)$, whereas in normal subjects the correlation between these two variables was negative $(n=70, r=$ $-0.358, p<0.01)$. No significant correlation was found between insulin and potassium concentrations.

\section{Discussion}

The present study indicates that mildly diabetic patients show a rise in plasma potassium induced by acute hyperglycaemia. This effect is probably initiated by an osmotic redistribution of potassium from the intracellular to the extracellular fluid compartment $[9$, 16].

Most previous reports of severe impairment of potassium homeostasis in diabetics were based on insulin-dependent patients, already treated, in whom insulin measurements were obviously not possible [3,5], and the majority of these patients had a co-existent hyporeninaemic hypoaldosteronism syndrome. Therefore it was thought that hyperglycaemia might induce alterations in transcellular potassium distribution and lead to clinically dangerous hyperkalaemia only in the presence of a combined deficiency of insulin and aldosterone [1].

Of note in the present study is the demonstration, for the first time, that newly diagnosed diabetic patients, none of whom had hyporeninaemic hypoaldosteronism, had a defect in potassium homeostasis manifested by a prompt rise of plasma potassium induced by hyperglycaemia. The effect of insulin on the net cellular potassium uptake in peripheral tissues clearly depends on the serum insulin level achieved
[17-19]; it is of particular interest that in Type 2 diabetic patients with clear insulin responses to hyperglycaemia, the plasma potassium showed a significant rise which contrasts with the lack of change seen in normal subjects.

The rise in plasma potassium in Type 2 diabetic patients would thus seem to represent a relative "endorgan resistance' to insulin-stimulated potassium transport. It may be similar to the insulin resistance which has been described for intermediary metabolism of carbohydrates in obese non-insulin-dependent diabetics [20,21]. Obesity itself might be relevant, since the subgroup of normal obese control subjects may have been protected from the hyperkalaemic effect by the higher insulin responses. The greater rise in potassium in our diabetics when compared with normal subjects, is not simply due to the fact that the normal subjects sustained a lesser rise in plasma glucose. Goldfarb et al. [1] raised the plasma glucose in normal subjects to high levels with intravenous infusions, yet found no rise in serum potassium; indeed they reported a fall which was attributed to the insulin response.

It has been reported recently that an oral glucose load suppresses aldosterone levels, but without change in plasma renin activity, in normal children and adolescents [22]. Our data confirm this for adults, and we also show that similar, but not greater, suppression occurs in diabetics; in addition, deoxycorticosterone is also suppressed. In the face of an increasing extracellular potassium concentration, this fall in mineralocorticoid levels, shown in the diabetics after oral glucose, would appear 'inappropriate'. It might be caused by potassium depletion in the adrenal glomerulosa cells, due to the osmotic effect mentioned above.

In conclusion, this study gives further evidence of the role of insulin in glucose-induced hyperkalaemia in untreated diabetics who are free of complications. It is highly suggestive that some form of tissue resistance to insulin-stimulated potassium uptake is present in Type 2 diabetes.

Acknowledgements. J.R. gratefully acknowledges a Scholarship from the British Council and the Social Security System of Costa Rica, and IEB a Scholarship from the Fundacion Gran Mariscal de Ayacucho, Venezuela. GFJ was generously supported by CibaGeigy.

We thank Dr. I.Trayner who kindly measured the potassium levels.

\section{References}

1. Goldfarb S, Cox M, Singer I, Goldberg M (1976) Acute hyperkalaemia induced by hyperglycaemia: hormonal mechanisms. Ann Intern Med 84:426-432 
2. Viberti GC (1978) Glucose-induced hyperkalaemia: a hazard for diabetics. Lancet 1:690-691

3. Perez GO, Lespier L, Knowles R, Oster JR, Vaamonde CA (1977) Potassium homeostasis in chronic diabetes mellitus. Arch Intern Med 137: 1018-1022

4. Phelps KR, Lieberman RL, Oh MS, Carroll HJ (1980) Pathophysiology of the syndrome of hyporeninaemic hypoaldosteronism. Metabolism 29: 186-199

5. DeFronzo RA, Sherwin RS, Felig P, Bia M (1977) Non-uremic diabetic hyperkalemia. Arch Intern Med 137: 842-843

6. Cannon PJ, Ames RP, Laragh JH (1966) Relation between potassium balance and aldosterone secretion in normal subjects and in patients with hypertensive or renal tubular disease. $\mathbf{J}$ Clin Invest 45:865-879

7. Santusanio F, Faloona GR, Knochel JP, Unger RH (1973) Evidence for a role of endogenous insulin and glucagon in the regulation of potassium homeostasis. J Lab Clin Med 81: 809-817

8. Hiatt N, Yamakawa T, Davidson MB (1974) Necessity for insulin in transfer of excess infused $\mathrm{K}$ to intracellular fluid. Metabolism 23: 43-49

9. Cox M, Sterns R, Singer I (1978) The defense against hyperkalaemia: the roles of insulin and aldosterone. N Engl J Med 299: $525-532$

10. Stat Bull Metrop Life Insur Co (1959) 40:3

11. Kurtz AB, Barter FH (1976) Radioimmunoassays for aldosterone and deoxycorticosterone in plasma and urine. Steroids 28 : 133-142

12. Cope CL, Loizou S (1973) Simplification of urinary aldosterone measurement by radioimmunoassay. J Clin Pathol 26: 628-634

13. Cope CL, Loizou S (1975) Deoxycorticosterone excretion in normal, hypertensive and hypokalaemic subjects. Clin Sci Mol Med 48: 97-105

14. Murphy BP, Engelberg W, Pattee CJ (1963) Simple method for the determination of plasma corticoids. J Clin Endocrinol 23: 293-300
15. Welborn TA, Fraser TR (1968) The double-antibody immunoassay of insulin. Diabetologia $1: 211-218$

16. Adler S, Anderson B, Zelt B (1975) Effect of osmolarity of intracellular $\mathrm{pH}$ of rat diaphragm muscle. Am J Physiol 228: $725-729$

17. Andres R, Baltzan MA, Cader G, Zierler KL (1962) Effect of insulin on carbohydrate metabolism and on potassium in the forearm of man. J Clin Invest $41: 108-115$

18. Guerra SMO, Kitabchi AE (1976) Comparison of the effectiveness of various routes of insulin injection: insulin levels and glucose response in normal subjects. J Clin Endocrinol Metab 42: $869-874$

19. DeFronzo RA, Felig P, Ferrannini E, Wahren J (1980) Effect of graded doses of insulin on splanchnic and peripheral potassium metabolism in man. Am J Physiol 238: 421-427

20. Reaven GM, Bernstein R, David B, Olefsky JM (1976) Nonketotic diabetes mellitus: insulin deficiency or insulin resistance? Am J Med 60: 80-88

21. Olefsky JM (1976) The insulin receptor: its role in insulin resistance of obesity and diabetes. Diabetes 25: 1154-1162

22. Hochberg Z, Dickerman Z, Kaufman H, Laron Z (1980) Evaluation of the renin-aldosterone system during hypo- and hyperglycaemia in children and adolescents. Hormone Res 12: $16-21$

Received: 10 April 1981

and in revised form: 12 October 1981

Dr. G. F. Joplin

Department of Medicine

Endocrine Unit

Royal Postgraduate Medical School

Du Cane Road

London W12 OHS, UK 